\title{
Editorial
}

\section{ABCES Jurídicos: una estrategia de divulgación del derecho}

\author{
Clara María Mira González ${ }^{1 凶}$, Sandra Janeth Tamayo Múnera ${ }^{2 \llbracket}$
}

${ }^{1}$ Docente, Coordinadora de Investigación e Innovación y editora de la Revista CES Derecho de la Facultad de Derecho de la Universidad CES. Abogada, especialista en gerencia de la seguridad social, especialista en estudios internacionales, magíster en ciencia política y candidata a doctora en derecho.

2 Docente, Directora del Consultorio Jurídico y Centro de Conciliación de la Facultad de Derecho de la Universidad CES. Abogada, especialista en derecho de familia, conciliadora en derecho y magister.

Fecha correspondencia:

Recibido: noviembre 23 de 2021.

Revisado: noviembre 23 de 2021

Aceptado: noviembre 23 de 2021.

\section{Forma de citar:}

Mira, Clara María; Tamayo,

Sandra Janeth. "ABCES Jurídicos:

una estrategia de divulgación del derecho" En: Revista CES

Derecho. Vol. 12, No. 2, julio a

diciembre de 2021, p. 1-2.

https://dx.doi.org/10.21615/

cesder.6496

\section{Open access}

(C) Derecho de autor

Licencia creative commons

Ética de publicaciones

Revisión por pares

Gestión por Open Journal System DOI: $10.21615 /$ cesder.6496

ISSNe 2145-7719

Publica con nosotros
Los estudiantes de la Facultad de Derecho de la Universidad CES que cursan el consultorio jurídico, presentan de manera semestral, los boletines ABCES.

Estos boletines consisten en la revisión minuciosa de un tema jurídico de los que habitualmente son competencia del Consultorio Jurídico, con el objeto de presentarlo a la comunidad en general y con ello empoderarla y clarificar el uso de mecanismos y figuras jurídicas.

Quienes inician su contacto con la práctica jurídica, en este caso, nuestros estudiantes, comienzan su contacto con la vida profesional en el Consultorio Jurídico y su Centro de Conciliación. Esta primera práctica constituye el contacto más directo desde su quehacer académico con la vida cotidiana y con el quehacer jurídico con la atención de usuarios en condición de vulnerabilidad económica y jurídica, y con ello prestan un servicio social.

La solución de conflictos jurídicos simples y sencillos y las asesorías jurídicas no son ajenas a la investigación jurídica, por ende, el proceso de elaboración de un ABCES Jurídico tiene en cuenta todo un proceso investigativo, que consiste en la selección inicial de una temática dentro de la práctica del 
Consultorio Jurídico y su justificación a partir de la no duplicidad del misma, de la novedad de la temática y finalmente de la importancia para la comunidad académica y para la práctica del consultorio jurídico.

Una vez validada la temática, el proceso continúa con la elaboración del boletín. Los estudiantes, a partir de un sistema de preguntas y respuestas simples, construyen el llamado $A, B C$, de una temática en derecho que permite de manera clara y sencilla poner al alcance del público en general un tema del derecho.

Desde el primer semestre del año 2017 se obtiene el ISSN de esta publicación periódica y además se rediseña la página de las publicaciones por internet, a la fecha se ha realizado publicación de un aproximado de 90 boletines ABCES.

En dichas publicaciones se ha profundizado en diferentes temáticas tales como: la regulación del proceso de liquidación de la sociedad conyugal; el funcionamiento y trámite de los apoyos judiciales para personas mayores de edad con discapacidad; la forma en la que funcionan los derechos sociales en el sistema interamericano, las modalidades; los sujetos y características de la violencia intrafamiliar; asuntos sobre la custodia compartida y el teletrabajo en Colombia.

Los invitamos a consultar esta publicación que nos llenan de orgullo en nuestra facultad.

https://editorial.ces.edu.co/boletin-abces-juridico/ 